\title{
A bidirectional Optimality Theoretic analysis of multiple negative indefinites in Afrikaans
}

\author{
Kate Huddlestone \\ Department of General Linguistics, Stellenbosch University, South Africa \\ E-mail: katevg@sun.ac.za \\ Henriëtte de Swart \\ Utrecht Institute of Linguistics OTS, Utrecht University, The Netherlands \\ E-mail: h.deswart@uu.nl
}

\begin{abstract}
In the literature on negation, Afrikaans is generally categorised as a negative concord language. Unlike most other negative concord languages though, utterances containing multiple indefinites in the scope of negation are typically produced with a combination of one negative indefinite and one (or more) non-negative indefinite, or negative polarity item, as in (i).
\end{abstract}

(i) Ons het niemand ooit daar gesien nie.

we have nobody ever there PST-see SN

'We never saw anybody there.'

However, although prohibited in formal, standard Afrikaans, where such utterances are prescriptively assigned a double negation meaning $\left(\neg \exists \mathrm{x}_{1} \neg \exists \mathrm{x}_{2}\right)$ and produced with a specific prosodic contour, in colloquial Afrikaans it is also possible to produce multiple negative indefinites with a single, or negative concord, meaning, as in (ii).

(ii) Ons het niemand nooit daar gesien nie.

we have nobody ever there PST-see SN

'We never saw anybody there.' $\left(\neg \exists \mathrm{x}_{1} \exists \mathrm{x}_{2}\right)$

Standard analyses of negative concord as presented in the literature do not account for the alternation of indefinites and negative indefinites in (i) vs. (ii), or the potential availability of both negative concord and double negation readings for the utterance in (ii). Perception experiments show that grammaticality judgements, by native speakers of Afrikaans, of multiple negative indefinites presented as auditory stimuli exhibit gradient acceptability in relation to combinations of negative indefinites and non-negative indefinites. Furthermore, this experimental data indicates that listeners use sentence prosody to assist in the interpretation of potentially ambiguous sentences containing multiple negative indefinites. The gradience of acceptability of multiple negative indefinite combinations is mirrored in turn by the frequency 
of such constructions in a written corpus of Afrikaans. In this paper, we account for this variation in the expression and interpretation of multiple indefinites in the scope of negation within the framework of stratified bidirectional Optimality Theory (OT). Such an analysis fills a gap in the typology of negation in accounting for alternation between negative and nonnegative indefinites in the production of standard and colloquial Afrikaans, as observed through corpus and experimental data, and allows for a prosodically constrained ambiguity between single and double negation readings.

Keywords: Negation, negative indefinites, Afrikaans, Optimality Theory, syntax-semantics interface

\section{Introduction}

In the literature on negation, Afrikaans is generally categorised as a negative concord language, a language which makes use of multiple instances of negation to express a single negation, as Afrikaans sentences typically contain a sentence-medial negative marker nie, or a negative indefinite as well as a sentence-final negative marker nie (indicated by SN in the gloss), as illustrated in (1). ${ }^{1}$

(a)

$$
\begin{array}{lll}
\text { Ons } & \text { het } & \text { nie } \\
\text { we } & \text { have } & \text { not }
\end{array}
$$

'We didn't come.'

(b)

$$
\begin{array}{ll}
\text { gekom } & \text { nie. }^{2} \\
\text { PST-come } & \mathrm{SN}
\end{array}
$$

$\begin{array}{lllll}\text { Ons het niemand daar gesien } & \text { nie. } \\ \text { we have nobody there } & \text { PST-see } & \text { SN } \\ \text { 'We didn't see anybody there.' } & & \end{array}$

Van der Wouden (1994), following and expanding on Den Besten (1986), characterises this pattern of negative concord as "negative doubling", defining it as the situation in which "a distinguished negative element shows up in all sentences that contain a negative expression". This type of negative concord is contrasted with "negative spread", in which "the negative feature is 'spread' or distributed over any number of indefinite expressions within its scope" (Van der Wouden 1994:95).

Negative spread is characteristic of most negative concord languages as, in negative concord languages in general, multiple indefinites in the scope of negation must be realised by multiple

\footnotetext{
${ }^{1}$ The term "negative indefinite" is used, following Penka (2007), in a descriptive manner to refer to both negative quantifiers, such as nobody or nothing in English, and to the so-called "n-words", a term first coined by Laka (1990) for the indefinite pronouns that participate in negation in negative concord languages. The analysis in this paper relies on the uniform interpretation of n-words and negative quantifiers as negative indefinites ( $\neg \exists$; cf. De Swart 2010). In Afrikaans, negative indefinites are the nominal and adverbial negative elements niemand ('nobody'), geeneen ('not one'), nooit ('never'), nêrens ('nowhere'), niks ('nothing'), as well as the negative determiners geen and $g$ ' $n$ ('no').

2 The focus of this paper is not on the expression of sentential negation by sentential markers of negation, but rather the expression of indefinites under negation. For further literature that deals specifically with discontinuous negation in Afrikaans, the reader is referred to Den Besten (1986), Robbers (1992), Donaldson (1993), Ponelis (1993), Bernini and Ramat (1996), Oosthuizen (1998), Bell (2004), Molnárfi (2004), and Biberauer $(2008,2009)$.
} 
negative indefinites (MNIs), expressing a single negation, as illustrated by the sentences in (2). In such cases, the interpretation of MNIs can be analysed through resumptive quantification (De Swart and Sag 2002). ${ }^{3}$
(a)

$\begin{array}{ll}\text { Nessuno } & \text { ha } \\ \text { nobody } & \text { has }\end{array}$
telefonato
$a$
'Nobody called anybody.'
(b)

$\begin{array}{llll}\text { Personne } & a & \text { rien } & \text { dit. } \\ \text { nobody } & \text { has } & \text { nothing } & \text { said }\end{array}$
'Nobody said anything.'
(c) Nikdo nedá nikomu nic.
nobody SN-gives nobody nothing
'Nobody gives anything to anyone.'

nessuno.

(Italian)

(Zeijlstra 2004:62)

(Spoken French)

(De Swart 2010:46)

(Czech)

(Zeijlstra 2004:62)

Unlike other negative concord languages though, in colloquial Afrikaans, when producing negative concord utterances containing multiple indefinites in the scope of negation, it is possible to either combine a negative indefinite and one or more non-negative indefinites, as in (3), or, less commonly, combine MNIs, as in (4). ${ }^{4}$

$\begin{array}{llll}\text { Niemand het iets } & \text { gesien } & \text { nie. } \\ \text { no-one } & \text { have anything } & \text { PST-see } & \text { SN } \\ \text { 'No-one saw anything.' } & & \end{array}$

$\begin{array}{llll}\text { Niemand } & \text { het } \quad \text { niks } & \text { gesien } & \text { nie. } \\ \text { no-one } & \text { have nothing } & \text { PST-see } & \text { SN } \\ \text { 'No-one sees anything.' }\left(\neg \exists \mathrm{x}_{1} \exists \mathrm{x}_{2}\right) & & \end{array}$

However, unlike colloquial Afrikaans, standard Afrikaans, as exemplified in prescriptive grammars, does not allow MNIs to co-occur with a single negation meaning. The only acceptable option is the negative indefinite/non-negative indefinite (NI-NNI) combination, illustrated in (3) above. Sentences containing MNIs are prescriptively assigned a double negation meaning, as in (5)..$^{5}$

\footnotetext{
${ }^{3}$ De Swart and Sag's (2002) analysis makes use of May’s (1989) operation of absorption, which interprets a sequence of negative indefinites $\mathrm{NO}_{\mathrm{x} 1}, \ldots \mathrm{NO}_{\mathrm{xn}}$ as a polyadic quantifier complex (May 1989, Van Benthem 1989, Keenan and Westerståhl 1997). According to De Swart (2010:38), while absorption as resumption goes beyond standard generalised quantifier theory, it is compositional in a higher order theory of meaning, namely that of polyadic generalised quantifier theory. See section 3.2 for further elaboration.

${ }^{4}$ An anonymous reviewer queried whether there might not be instances where two negative indefinites and one non-negative indefinite co-occur, however no such constructions were found in the data, nor were they tested in the empirical study. Hence, this remains a question for further study.

${ }^{5}$ Sentences in both standard and colloquial Afrikaans that contain both a negative indefinite and sentence-medial nie, as well as sentence-final nie, also receive a double negation interpretation.

(i) Niemand het nie gehelp nie.

nobody have not helped SN

'Nobody didn't help', i.e. 'Everyone did help.'
} 


\begin{tabular}{|c|c|c|c|c|c|}
\hline $\begin{array}{l}\text { Niemand } \\
\text { no-one }\end{array}$ & $\begin{array}{l}\text { het } \\
\text { have }\end{array}$ & $\begin{array}{l}\text { niks } \\
\text { nothing }\end{array}$ & $\begin{array}{l}\text { gesien } \\
\text { PST-see }\end{array}$ & $\begin{array}{l}\text { nie. } \\
\text { SN }\end{array}$ & (Prescriptive Afrikaans) ${ }^{6}$ \\
\hline
\end{tabular}

Unsurprisingly, as is the case in typical double negation languages like English and Dutch, MNI constructions with a double negation meaning do not occur frequently in (standard) Afrikaans, and when they do, the utterance containing such a structure has to be produced with a very specific double negation intonation contour, given in Figure 1 below. ${ }^{7}$ Specifically, an MNI combination expressing a double negation meaning needs to be produced with what is termed a "contradiction contour" (Liberman and Sag 1974). This means that the utterance is produced with a nuclear accent $\mathrm{L}+\mathrm{H}^{*}$ on the final negative indefinite, and finished off with an L-phrase accent and an $\mathrm{H} \%$ boundary tone (i.e. a rising pitch associated with the stressed syllable followed by a complex falling-rising tone) ${ }^{8}$

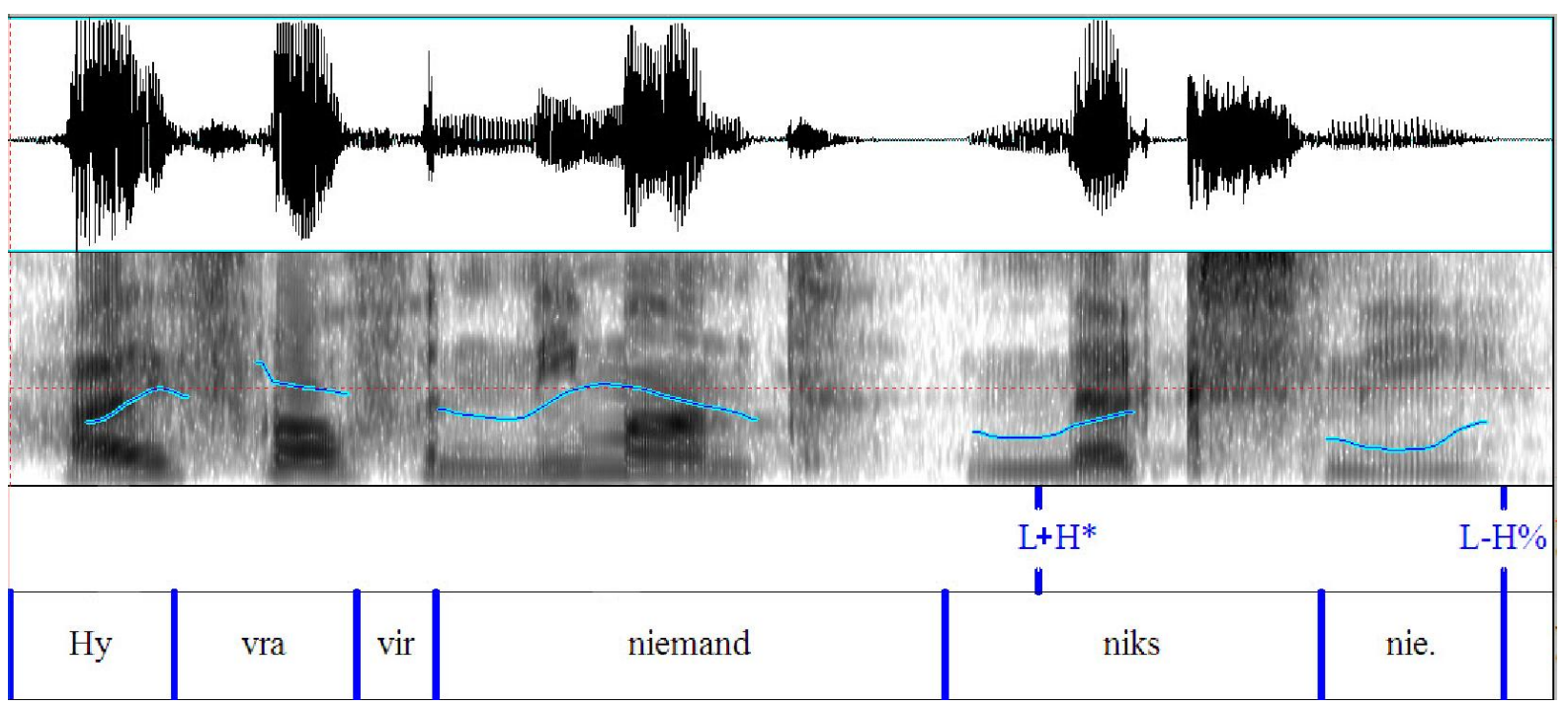

Figure 1. Intonation contour for double negation utterance

In contrast, when MNIs with a negative concord meaning are produced in (colloquial) Afrikaans, the intonation contour used most often is the "declarative contour" (Beckman and Elam 1997:15), as illustrated in Figure 2. The occurrence of MNIs with a single negation meaning does not exclude the possibility that, even in colloquial Afrikaans, such constructions may be assigned a double negation interpretation, as in (5) above, if produced with the contour in Figure 1. However,

(ii) Hy het nie niks gedoen nie.

he have not nothing done SN

'He didn't do nothing', i.e. 'He did do something.'

However, as noted in fn. 2, this article does not attempt to account for the co-occurrence of negative indefinites and the sentential marker of negation, sentence-medial nie. Cf. De Swart (2010) for an explanation of the double negation readings obtained in examples (i) and (ii) along the same lines as the co-occurrence restrictions between sentential negation and negative indefinites in French.

${ }^{6}$ All examples in this paper are colloquial Afrikaans unless otherwise labelled.

${ }^{7}$ Various authors have discussed this intonation contour requirement in relation to (Verum) Focus, cf. Biberauer and Zeijlstra (2012), Puskás (2006, 2012). See also Prieto, Borràs-Comes, Tubau and Espinal (2013) in regard to the importance of intonation in the interpretation of double negation in Spanish and Catalan.

${ }^{8}$ The prosodic notation of the contours was undertaken using Praat, a free software program for acoustic analysis of speech, designed by Paul Boersma and David Weenink (University of Amsterdam), and using the Guidelines for ToBI labelling (Beckman and Elam 1997). 
as we will show in the next section, such interpretations are somewhat difficult to elicit, and virtually impossible without appropriate prosody.

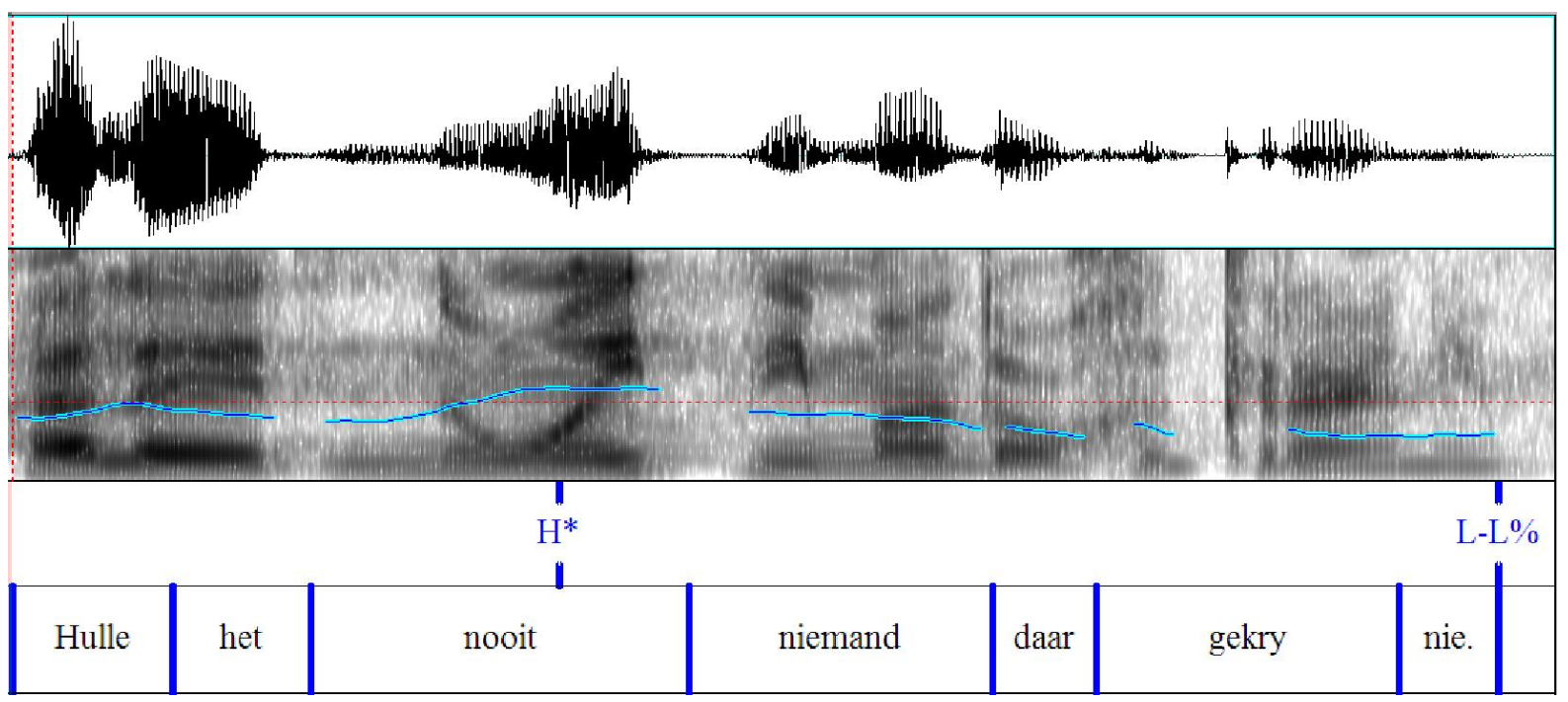

Figure 2. Intonation contour for negative concord utterance

That negative indefinites in standard, prescriptive Afrikaans cannot co-occur with other negative indefinites expressing a single logical negation, while at the same time always cooccurring with a marker of sentential negation, sentence-final nie, is a contradiction that is largely ignored in the literature (some exceptions being Molnárfi 2004, Biberauer 2009, Huddlestone 2010 and Biberauer and Zeijlstra 2012). Furthermore, standard analyses of negative concord as presented in the literature do not account for the alternation of indefinites and negative indefinites in (3) vs. (4), or the potential availability of both negative concord and double negation readings for the utterance given in (4) and (5). This distributional pattern is summarised in Table 1 below.

Table 1: Availability of meanings of MNIs in prescriptive and colloquial Afrikaans

\begin{tabular}{|l|c|c|}
\hline & $\neg \exists \mathrm{x}_{1} \exists \mathrm{x}_{2}$ & $\neg \exists \mathrm{x}_{1} \neg \exists \mathrm{x}_{2}$ \\
\hline Prescriptive Afrikaans & No & Yes \\
\hline $\begin{array}{l}\text { Colloquial Afrikaans } \\
\text { (neutral intonation) }\end{array}$ & Yes & No \\
\hline $\begin{array}{l}\text { Colloquial Afrikaans } \\
\text { (special intonation) }\end{array}$ & No & Yes (?) \\
\hline
\end{tabular}

In the current paper, we account for this variation in the expression, and potential ambiguity in the interpretation, of indefinites in the scope of negation within the framework of (bidirectional) Optimality Theory (OT), a framework that naturally accommodates possibly conflicting preferences by making use of a partially ranked, stratified grammar (Anttila 1997, Bouma 2008, 2011). As Anttila and Fong (2004:1254) note, "it is precisely in the domain of variation and ambiguity that OT can provide genuinely new insights and derive results that are difficult to achieve in other frameworks". 
This paper is organised as follows. In section 2 we examine, firstly, the empirical evidence for MNIs and their preferred interpretation in a written corpus of Afrikaans and through perceptual experiments; secondly, we discuss selected other approaches to the analysis of MNIs in Afrikaans. In section 3 we provide our analysis of these MNIs in Afrikaans, first providing a brief motivation for the use of (bidirectional) OT as a framework in which to analyse the data, and then discussing indefinites in the scope of negation in prescriptive Afrikaans within a bidirectional OT framework. Finally, in section 3.3 we argue that a stratified bidirectional OT grammar can account for the optionality in expression and apparent ambiguity in interpretation of negative indefinites found in colloquial Afrikaans.

\section{Multiple negative indefinites in (colloquial) Afrikaans}

\subsection{Acceptability and preferred interpretation of multiple negative indefinites}

In order to develop an analysis of constructions containing MNIs in Afrikaans, it is necessary to determine (i) their acceptability to native speakers of Afrikaans, (ii) their frequency in Afrikaans, and (iii) the default meaning assigned to such constructions.

In order to address (i) and (iii), a perception experiment was set up in order to test Afrikaans native speakers' judgements of spoken utterances containing MNI constructions, as well as to elicit judgements on the meaning of various utterances containing negative indefinite combinations. ${ }^{9}$ The perception experiment, administered online, involved a questionnaire consisting of 120 utterances, of which 14 contained MNIs, as illustrated by the examples in (6ac) ${ }^{10}$ These utterances were read twice, once with neutral prosody and once with double negation prosody, as described in section 1. The questionnaire also contained 14 utterances consisting of NI-NNI combinations, as illustrated in (6d). Participants were asked to judge the acceptability of each utterance on a seven-point Likert-type scale. The endpoints were described, with 1 being "acceptable in Afrikaans" and 7 being "unacceptable in Afrikaans", but the intermediate scale values were not given labels. Participants were also asked to indicate the meaning of each utterance. In the case of utterances containing MNIs, participants were given three options: a meaning that corresponded to the double negation interpretation of the utterance, a meaning that corresponded to the negative concord interpretation of the utterance, and an option indicating that neither of the two meanings was appropriate.

(a)

$$
\begin{aligned}
& \text { Hy vra vir niemand niks nie. } \\
& \text { he ask for nobody nothing SN } \\
& \text { 'He doesn't ask anybody anything.' (negative concord) } \\
& \text { 'He asked nobody nothing.' }
\end{aligned}
$$

(b) Ekhet niks nêrens gekoop nie.

I have nothing nowhere PST-buy SN

'I didn't buy anything anywhere.' (negative concord)

'I bought nothing nowhere.' (double negation)

\footnotetext{
${ }^{9}$ The utterances were presented as auditory stimuli in an attempt to avoid the prescriptive attitudes that are often associated with written forms.

${ }^{10}$ See Huddlestone (2010) for further details about the perception experiment.
} 
(c) Hulle het nooit niemand daar gekry nie.

They have never nobody there PST-get SN

'They never found anybody there.' (negative concord)

'They never found nobody there.' (double negation)

(d)

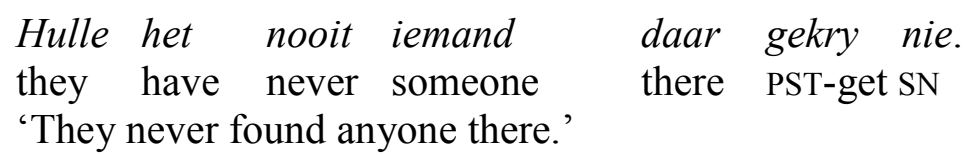

The questionnaire was administered on two occasions to a total of forty native speakers of Afrikaans, postgraduate and undergraduate students who were (or had been in the past) registered for either General Linguistics or Afrikaans and Dutch at Stellenbosch University; the questionnaire was completed via the online learning environment at Stellenbosch University. All the test items were randomised multiple times to create different versions for each group of participants. Each version of the questionnaire was then divided into two parts in such a way that no utterance (even if pronounced with a different intonation contour) was repeated in the same part of the questionnaire. All the utterances were read several times and the recordings that appeared to capture the intended interpretation the best were selected for inclusion in the study. The utterances were read by two female postgraduate research assistants in the General Linguistics department. Although not trained speakers, it was judged that the level of linguistic awareness and the experience attained as a bilingual language instructor were sufficient criteria to make the readings reliable from a prosodic disambiguation point of view. In addition, there has been criticism levelled at studies that make use of, for example, professional newscasters, as production results of studies using speakers who are trained to produce disambiguating contours may not accurately reflect the prosody of natural conversation and thus may misrepresent the degree of prosodic disambiguation found in everyday speech (Schafer, Speer, Warren and White 2000).

Two way ANOVAs were conducted to determine the effects of prosodic contour on acceptability and on percentage of correct interpretations of utterances containing negative indefinite combinations. A cross-tabulation was carried out to compare percentages of correct interpretations between utterances produced with a neutral (negative concord) prosodic contour, with those produced with a double negation prosodic contour. ${ }^{11}$ Summary statistics are presented in histograms and frequency tables. Figure 3 presents the results of the comparison of acceptability judgements of utterances produced with a neutral prosodic contour with those produced with a double negation prosodic contour. From this we see that there was no statistically significant difference between the mean acceptability of utterances containing combinations of negative indefinites produced with a neutral prosodic contour vs. utterances produced with a double negation prosodic contour in the perception experiment, $F(1,38)=.039$ $p=.85$.

\footnotetext{
${ }^{11}$ These results exclude two participants who failed to choose any interpretation, or indicated that neither the negative concord nor the double negation meaning was appropriate, for all the utterances containing MNIs presented in the questionnaire.
} 


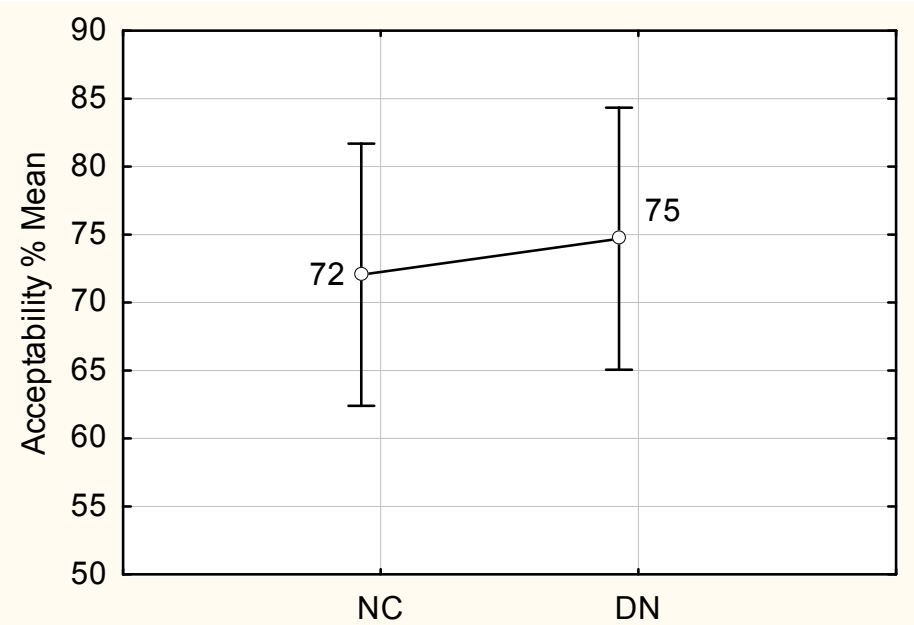

Figure 3. Acceptability means - prosodic contour

The fact that there is no statistically significant difference in mean acceptability judgements based on prosodic contour, means that participants produced much the same acceptability judgements for utterances produced with a neutral prosodic contour as they did for utterances produced with a double negation prosodic contour. Therefore, we can group together the results of the utterances produced with different prosodic contours in our examination of the results of the perception experiment, as they relate to mean acceptability.

As we can see in Figure 4, the results of these perception experiments show that grammaticality judgements of MNIs presented as auditory stimuli exhibit gradient acceptability in relation to NI-NNI combinations.

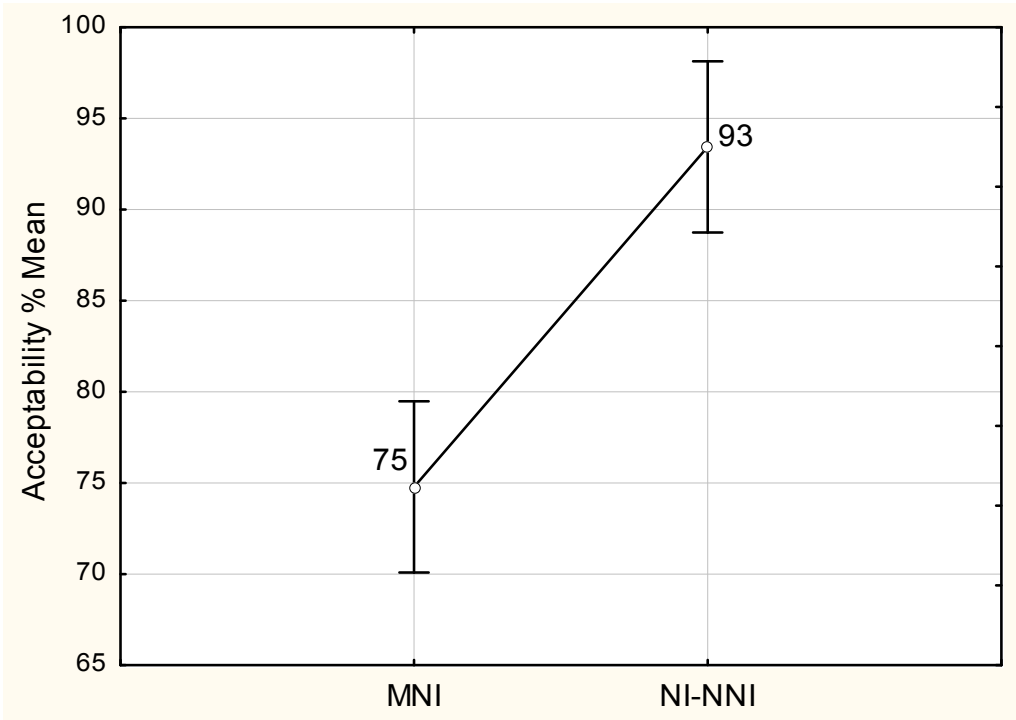

Figure 4. Acceptability means - MNI vs. NI-NNI combinations

There is a statistically significant difference between the mean acceptability of utterances containing MNI combinations and the mean acceptability of utterances containing NI-NNI combinations, $F(1,38)=53.94, p=.00$. Specifically, utterances containing NI-NNI combinations have a significantly higher mean acceptability (93\%) than utterances containing MNI 
combinations (75\%). These results show that although MNI combinations are generally acceptable to native speakers when presented as auditory stimuli, they do not score as high as the standard Afrikaans form for expressing multiple indefinites in the scope of negation, namely by a single negative indefinite with n-1 indefinites in its scope.

Gradience of acceptability of MNI combinations is reflected in turn by the frequency of such constructions in a written corpus of Afrikaans. In order to address (ii) the frequency of MNI combinations, and (iii) the default meaning assigned to such constructions, a corpus study was undertaken using the Pharos corpus of written Afrikaans which consists of articles from the various NasPers Afrikaans-language newspapers (Beeld, Die Burger, Landbouweekblad and Rapport) and magazines (Dit, Huisgenoot, Insig, Sarie and TV Plus), as well as various Afrikaans fiction and non-fiction books published by Pharos and covering a time span of 21 years, from 1986 until 2006. ${ }^{12}$ An analysis of the corpus shows that of the total 2928 negative sentences containing multiple adjacent, existentially quantified variables found in the corpus, $96 \%$ contain an NI-NNI combination. The remaining $4 \%$ of these sentences contain multiple adjacent negative indefinites. These results are summarised in Table 2.

Table 2: Frequencies for expression of indefinites under negation

\begin{tabular}{|l|c|c|}
\hline Frequencies for indefinites under negation & $\begin{array}{c}\text { No. of } \\
\text { occurrences }\end{array}$ & $\begin{array}{c}\text { Percentage of } \\
\text { total }\end{array}$ \\
\hline negative indefinite + indefinite & 2800 & $96 \%$ \\
\hline multiple negative indefinites & 128 & $4 \%$ \\
\hline Total & 2928 & $100 \%$ \\
\hline
\end{tabular}

As pointed out in section 1, it is possible to get combinations of MNIs with both a double negation and a negative concord interpretation. What needs to be determined is the prevalence of double negation interpretations of MNI combinations in comparison to negative concord interpretations of these constructions. On close examination of the corpus data, it was found that $96 \%$ of the sentences containing MNIs have a negative concord interpretation, while only $4 \%$ have a double negation interpretation. These results are summarised in Table 3.

Table 3: Frequencies for interpretations of multiple NI combinations

\begin{tabular}{|l|c|c|}
\hline Interpretation of MNI combinations & $\begin{array}{c}\text { No. of } \\
\text { occurrences }\end{array}$ & $\begin{array}{c}\text { Percentage of } \\
\text { total }\end{array}$ \\
\hline negative concord interpretation & 123 & $96 \%$ \\
\hline double negation interpretation & 5 & $4 \%$ \\
\hline Total & 128 & $100 \%$ \\
\hline
\end{tabular}

So, although constructions with more than one negative indefinite are not common in Afrikaans, the occurrence of MNIs is indeed observed. ${ }^{13}$ And, contrary to the expectations established by

\footnotetext{
${ }^{12}$ Pharos is a South African publisher specialising in Afrikaans monolingual and Afrikaans and English bilingual dictionaries. We are indebted to them for the use of their corpus.

${ }^{13}$ The majority of all the instances of multiple negative indefinite constructions found in the data, came from either sports reports or from readers' letters to the various newspapers or were reported speech, all more colloquial in
} 
prescriptive grammars of standard Afrikaans, these MNI constructions are almost always given a single negation or negative concord interpretation. The examples below, taken from the Pharos corpus, illustrate the occurrence in Afrikaans of MNIs. In examples (7)-(9), we see the occurrence of MNI combinations, nooit niemand, niks niemand and nooit niks respectively, with a single negation interpretation, while in (10) and (11) we see this last combination, nooit niks, in contexts that result in a double negation interpretation. ${ }^{14}$ In each case, the intended interpretation is recoverable from the context.

(7) "Hulle moes haar vreeslik geslaan het," het hy gesê. "Sy was so 'n saggeaarde kind. they must her terribly PST-hit have have he PST-say she was so a softhearted child Sy sou nooit niemand seergemaak het nie," het mnr. Hill gesê. she would never nobody sore-PST-make have SN have Mr. Hill PST-say " "They must have hit her terribly," he said. "She was such a soft-hearted child. She would never have hurt anybody." said Mr Hill.'

(Beeld 1996-03-29)

(8) Wat hy in sy private lewe doen, het niks met niemand uit te waai nie. Sy what he in his private life do have nothing with nobody out to wave SN his ondersteuners behoort nog net so mal oor hom te wees. supporters should still just so crazy over him to be 'What he does in his private life, doesn't have anything to do with anybody. His supporters should still be just as crazy about him.'

(Huisgenoot 2001-04-11)

(9) Ons hoor nooit niks van die polisie nie. Ek weet nie eens wie ondersoek die saak we hear never nothing from the police SN I know not even who investigate the case nou nie -- vier verskillende speurders het dit al gehad. Ek soek geregtigheid. now SN four different detectives have it already PST-have I seek justice

'We don't hear anything from the police. I don't even know who is now investigating the case -- four different detectives have already been on it. I am looking for justice.'

(Beeld 2004-02-24)

(10) As die grondstruktuur reg is, sal jy ook in swakjare'noes hê. Dit sal min if the ground-structure right is will you also in bad years a harvest have it will little wees, maar nooit niks, soos wat by konvensionele boere verlede jaar die geval was. be but never nothing like what by conventional farmers last year the case was 'If the ground structure is correct, you will still have a harvest in bad years. It will be small, but never nothing, as was the case with conventional farmers last year.'

(Landbouweekblad 2000-04-28)

(11) "Ons doen eintlik net wat ons skoolleuse sê: hard werk, minder praat. Ons sê we do actually just what our school-motto say hard work less talk we say nooit ons het niks nie. Julle het ons mooi kitaar gesien," het mev. Mary Molete,

nature than formal news reports and editorials. These data therefore support the intuitions of native speakers of Afrikaans that MNI constructions occur predominantly in informal, colloquial speech.

${ }^{14}$ Examples (10) and (11) reflect two of the five instances where MNIs were used to express double negation meanings. 
never we have nothing SN you have our pretty guitar PST-see have Mrs. M-- Molete Afrikaansonderwyser, gesê. [...] "Ons het nie handboeke nie. Maar elke jaar doen Afrikaans-teacher PST-say we have not textbooks SN but each year do ons ons bes en God doen die res."

us our best and God do the rest

"“We actually do just what our school motto says: hard work, less talk. We never say we have nothing. You saw our pretty guitar." said Mrs Mary Molete, Afrikaans teacher.

[...] "We don't have textbooks. But every year we do our best and God does the rest."”

(Beeld 2005-05-24)

What is striking about the data in Tables 2 and 3 is the marked asymmetry between the occurrence of NI-NNI combinations and MNI combinations (there are far more occurrences of NI-NNI combinations than MNI combinations), and the inverse asymmetry observed for the interpretation of MNI combinations (the majority of occurrences of MNI combinations receives a negative concord interpretation). What must be noted, however, is the paucity of this data when it comes to the interpretation of MNI combinations. In order to address (iii) more comprehensively, the corpus data was supplemented with data from perception experiments, discussed above. By eliciting judgements on the meaning of various utterances containing negative indefinite combinations, the intention is to show that the marked preference for negative concord interpretations of MNI combinations is supported by native speaker intuitions. What becomes clear from the perception experiment data is that the prevalence of negative concord interpretations observed in the written corpus is borne out by the spoken data, with the negative concord interpretation of MNI combinations being the preferred interpretation.

Table 4 below provides the frequencies for the assignment of negative concord and double negation interpretations to the utterances produced with a neutral intonation contour. From these figures, we see a similar pattern to the one observed for the corpus data given in Table 2. In the perception experiment, however, the distribution of negative concord to double negation interpretations occurs in a ratio of 5:1, which is much higher for double negation interpretations than that observed in the corpus data. However, despite the fact that the percentages are not identical in both data sets, the broad observation holds, namely that there is a marked preference for negative concord interpretations of MNI combinations (when produced with a neutral intonation contour). ${ }^{15}$

Table 4: Frequencies for utterances produced with neutral intonation contour

\begin{tabular}{|l|c|c|}
\hline Neutral intonation & $\begin{array}{c}\text { No. of } \\
\text { occurrences }\end{array}$ & $\begin{array}{c}\text { Percentage of } \\
\text { total }\end{array}$ \\
\hline negative concord interpretation & 433 & $83 \%$ \\
\hline double negation interpretation & 90 & $17 \%$ \\
\hline Total & 523 & $100 \%$ \\
\hline
\end{tabular}

\footnotetext{
${ }^{15}$ As pointed out by an anonymous reviewer, it is possible to argue that a $17 \%$ occurrence of double negation interpretations falls within the noise range of the experiment, and therefore one could take this to be evidence against the possible ambiguity of MNIs in colloquial Afrikaans.
} 
Table 5 shows the frequencies for the assignment of negative concord and double negation interpretations to the utterances produced with a double negation intonation contour. We can see that there is a $65 / 35$ split in favour of the double negation interpretation for utterances produced with a double negation intonation contour. This provides evidence for the observation that the occurrence of MNIs with a single negation meaning in colloquial Afrikaans does not exclude the possibility that such constructions may be assigned a double negation interpretation if produced with an appropriate double negation prosodic contour.

Table 5: Frequencies for utterances produced with double negation intonation contour

\begin{tabular}{|l|c|c|}
\hline Double negation intonation & $\begin{array}{c}\text { No. of } \\
\text { occurrences }\end{array}$ & $\begin{array}{c}\text { Percentage of } \\
\text { total }\end{array}$ \\
\hline negative concord interpretation & 167 & $35 \%$ \\
\hline double negation interpretation & 309 & $65 \%$ \\
\hline Total & 476 & $100 \%$ \\
\hline
\end{tabular}

The fact that the data presented in Table 5 is less clear-cut than that in Table 4 may be a result of certain participants failing to take into account the intonation contour present. As Espinal and Prieto (2011) show in experiments related to the interpretation of double negation in Catalan, a contradictory intonation contour is crucial for Catalan listeners to correctly attain a double negation interpretation, so it is uncontroversial to expect the same in Afrikaans. This data further supports the claim that the negative concord interpretation of MNIs is the preferred interpretation for these structures and, when in doubt, a hearer tends to opt for the negative concord interpretation as the default interpretation.

A Chi-square test with Yates' continuity correction comparing the interpretations of the neutral vs. double negation interpretations revealed that the interpretation of an utterance differed significantly as a result of the intonation contour, $\chi 2(1, \mathrm{~N}=999)=236, \mathrm{p}=0.00$ (the Fisher exact test statistic value is 0 , with the result significant at $\mathrm{p}<0.01$ ).

What the data discussed in this section shows is that there is variation in the expression of indefinites in the scope of negation in Afrikaans, as well as in the interpretation of MNI combinations. It is possible to express a single negation both with an NI-NNI combination and with an MNI combination, and it is possible to assign either a double negation or a negative concord interpretation to an MNI combination (although the latter variation occurs almost exclusively with MNI utterances produced with a double negation prosody contour). In order to account for this variation and potential ambiguity, any analysis proposed must explain the occurrence of two possible forms to express a single meaning for the two possible interpretations of MNI combinations.

\subsection{Other approaches to the analysis of multiple negative indefinites in Afrikaans}

One possibility to account for the two possible interpretations of MNI combinations in Afrikaans would be to posit an analysis along the lines of Zeijlstra $(2004,2007)$ and characterise MNI combinations with negative concord interpretations as non-productive lexicalised expressions or Emphatic Multiple Negative Expressions (EMNEs). According to Zeijlstra, EMNEs differ from standard negative concord constructions in five ways: 
(i) EMNEs have an emphatic reading; negative concord constructions usually do not;

(ii) EMNEs are subject to strict adjacency conditions, contrary to negative concord constructions;

(iii) The first part of the EMNE must carry stress, otherwise it is ruled out;

(iv) The meaning of an EMNE is not always straightforward, contrary to most negative concord expressions;

(v) The formation of EMNEs is not productive; speakers generally differ with respect to which EMNE they accept and which they do not accept.

(Zeij1stra 2007:80-81)

Zeijlstra argues that EMNEs cannot be analysed as instances of negative concord that surface in double negation languages; his proposal is that, due to their idiosyncratic nature, EMNEs are in fact single lexical items despite their complex appearance. However, MNI combinations in Afrikaans are generally productive, are not subject to strict adjacency conditions, and are equivalent to the expression of negation by an NI-NNI combination, i.e. they generally carry no additional emphasis. As such, MNI combinations in Afrikaans fail to fulfil Zeijlstra's crucial characteristics of EMNEs (Zeijlstra 2007:79). Furthermore, as the perception experiment data shows, the negative concord interpretation of these constructions appears to be the default interpretation unless there is a very specific prosodic contour present. This is in fact the opposite of what Zeijlstra's analysis would predict. Rather, it is necessary to account for MNI combinations within an integrated theory of negative indefinites in Afrikaans.

A second possibility would be to account for this variation and ambiguity in terms of different registers or varieties of Afrikaans, such as formal vs. informal Afrikaans or standard vs. colloquial Afrikaans. The latter distinction is one that has been assumed to this point in the paper, and is one that underlies Biberauer and Zeijlstra's (2012) analysis of negative concord in Afrikaans. According to Biberauer and Zeijlstra, MNI combinations always yield a double negation reading in what they term "Afrikaans A" - the conservative variety of the spoken language, and the variety that we have characterised as standard, prescriptive Afrikaans - but that both double negation and negative concord readings are available in "Afrikaans B" - the variety that we have characterised as colloquial Afrikaans.

Biberauer and Zeijlstra (2012) adopt Zeijlstra's (2004) minimalist syntactic analysis of negative concord as an instance of syntactic agreement, with such agreement realised as a consequence of the operation Agree, involving elements that carry semantically interpretable and semantically uninterpretable features, respectively. According to Biberauer and Zeijlstra, negative indefinites in Afrikaans A are semantically negative, that is they carry an $[i \mathrm{Neg}]$ feature, while negative indefinites in Afrikaans B are semantically non-negative, that is they carry a $[u \mathrm{Neg}]$ feature. In both varieties, sentential negation markers are assumed to carry a $[u \mathrm{Neg}]$ feature, meaning that they are semantically non-negative. According to Biberauer and Zeijlstra, the $[i \mathrm{Neg}]$ feature carried by all negative indefinites in Afrikaans A means that all MNI combinations will yield a double negation interpretation. As with Zeijlstra's (2004) account of strict negative concord languages, Biberauer and Zeijlstra take the co-occurrence of negative indefinites with a negative concord interpretation to be evidence that these negative indefinites are semantically nonnegative and carry a $[u \mathrm{Neg}]$ feature. Therefore, in colloquial Afrikaans both the sentential 
negative marker and negative indefinites carry $[u \mathrm{NEG}]$ features which are checked against the covert negative operator $O p\urcorner{ }^{16}$

$$
\begin{array}{lll}
\text { Niemand } & \text { sien niks nie. } \\
\text { No-one } & \text { sees nothing SN } \\
\text { 'No-one sees nothing, } & \text { i.e. 'Everyone sees something.' }
\end{array}
$$

(b)

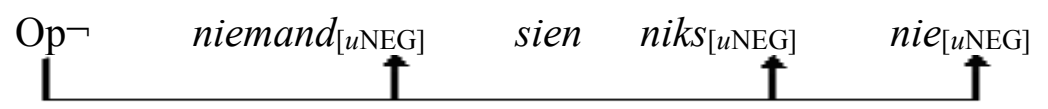

(Biberauer and Zeijlstra 2012:365)

Biberauer and Zeijlstra argue that one of the two respects in which Afrikaans B differs from Afrikaans A is that in colloquial Afrikaans MNIs may yield a negative concord reading in addition to the double negation reading that is obligatory in standard Afrikaans. In the case of double negation readings of MNIs in colloquial Afrikaans, the authors argue that it is the assignment of a special type of focus, namely Negative Verum Focus, to one of the negative indefinites which disrupts the agree relation, preventing a negative concord interpretation of the utterance. However, while this analysis appears to account for how combinations of MNIs are able to yield both a negative concord and a double negation interpretation, Biberauer and Zeijlstra do not provide an explanation for why it is still preferable in colloquial Afrikaans to use an NI-NNI combination in place of an MNI combination. As pointed out in the introductory section, the central focus of this paper is the potential ambiguity between negative concord and double negation interpretations of MNI combinations on the one hand, and the variation in the expression of multiple indefinites in the scope of negation on the other hand. In the next section, we provide our analysis of this variation, first providing a brief motivation for the use of (bidirectional) OT as a framework for the analysis.

\section{A bidirectional OT account of multiple indefinites in the scope of negation in Afrikaans}

\section{1. (Bidirectional) Optimality Theory}

Optimality Theory is a general theory of language and grammar that originated with explorations of the ability of optimisation principles, from research on neural network modelling, to provide insights into the structure of the language faculty (Prince and Smolensky 1997:1604). An optimisation approach to language entails that speakers select an optimal form for expressing a given meaning, while hearers, in turn, select an optimal interpretation for a given form. These optimal forms and meanings are determined on the basis of the application of various constraints which typically conflict, and an optimal form or meaning is taken to be one that best satisfies the total set of constraints. According to Hendriks, De Hoop, Krämer, De Swart and Zwarts (2010:2), an optimisation approach not only provides "a new way to tackle old problems in the areas of compositional semantics, lexical semantics, language acquisition and language typology, but such an approach may also allow for the integration of linguistic results with results from the wider field of cognitive science".

\footnotetext{
${ }^{16}$ De Swart (2010) argues against the view that a compositional analysis of negation and negative concord should be based on covert or empty negative operators, noting that "[i]f a truth-functional operator like $\neg$ can remain implicit in the sentence, or the negation particle is semantically potent in some sentences, but not others, the distinction between affirmation and negation is blurred" (De Swart 2010:35).
} 
In OT, a grammar consists of a ranked set of well-formedness constraints. These constraints apply simultaneously to representations of structures, are ordered in a constraint hierarchy according to strength, and are violable. A constraint may be violated but only in order to satisfy a stronger constraint. The assumption is that languages share the same set of constraints and that differences between languages are the result of the language-specific ordering of the same set of constraints. Constraints are of two types, namely markedness constraints, which are solely applicable to the form of the output and are blind to the form of the input, and faithfulness constraints. In syntax and semantics, faithfulness constraints amount to a relation of association, that is, they associate a particular form with a particular meaning. As such, they take into account both the input and the output. Markedness constraints entail that certain forms or meanings are preferred to other forms or meanings because they are unmarked.

For example, in the case of negation, FNEG - given in (13) - is a faithfulness constraint which requires that negation in the input be reflected in the output. In conflict with this constraint is the markedness constraint *NEG, given in (14), which aims at the reduction of structure in the output by avoiding negation.

\section{(13) FNEG}

Be faithful to negation, i.e. reflect the non-affirmative nature of the input in the output.

\section{*NEG}

Avoid negation in the output.

A ranking of FNEG higher than *NEG, given in (15), resolves the conflict and derives the fact that negative meanings are formally expressed in natural language.

\section{FNEG ॥*NEG}

We can illustrate the effect of this constraint ranking on the generation and interpretation of propositional negation in relation to the sentence in (16), with Tableaux 1 and 2 below. In OT, optimisation is typically represented in a tableau: the input to the optimisation is given in the top left-hand cell, while the possible outputs are given in the first column below the input. The constraints are given in the top row, ordered according to their constraint ranking. An asterisk (*) in a cell indicates a violation of a constraint, while an exclamation mark (!) indicates a fatal violation of a constraint. The pointing hand $\left(\sigma^{\odot}\right)$ represents the optimal candidate.

It is not raining.

In these tableaux, FNEG is ranked higher than *NEG, leading to the optimal candidate for the input in Tableau 1, the meaning $\neg$ rain, being the form that reflects the negation present in the input (It is not raining). For the input in Tableau 2, the form It is not raining, the optimal candidate is the meaning $\neg$ rain, which reflects the negation present in the input. 
Tableau 1: Generation of negative sentences

\begin{tabular}{|l|c|c|}
\hline$\neg$ rain & FNEG & $*$ NEG \\
\hline It is raining & $* !$ & \\
\hline It is not raining & & $*$ \\
\hline
\end{tabular}

Tableau 2: Interpretation of negative sentences

\begin{tabular}{|l|c|c|}
\hline It is not raining & FNEG & $*$ NEG \\
\hline rain & $* !$ & \\
\hline$\rightarrow$ rain & & $*$ \\
\hline
\end{tabular}

Bidirectional optimisation is a way of capturing the intuition that hearers not only rely on their own perspective, but also take into account the speaker's perspective when interpreting an input. Whether the opposite is also the case, i.e. whether speakers take into account both their perspective and the hearer's perspective when producing an output, is, however, a point of debate (cf. Zeevat 2000, 2006; Wilson 2001). In a bidirectional OT framework, optimality is defined in terms of pairs of a form $f$ and a meaning $m$, with form-meaning pairs that compete in one direction of optimisation being constrained by the outcomes of the other direction, and vice versa, and a form-meaning pair being an optimal pair if there is no pair with a better form or a better meaning. In bidirectional optimisation, a form-meaning pair $\langle f, m\rangle$ is optimal if and only if there is no other pair $\left\langle f^{\prime}, m\right\rangle$ such that $\left\langle f^{\prime}, m\right\rangle »\langle f, m\rangle$, and there is no other pair $\left\langle f, m^{\prime}\right\rangle$ such that $\langle f, m\rangle »\langle f, m\rangle$, where » is an ordering relation which can be read as "being less costly, being more harmonic, being more economical" (Blutner, De Hoop and Hendriks 2006:23). This means that form-meaning pairs that compete in one direction of optimisation are constrained by the outcomes of the other direction, and vice versa, and a form-meaning pair is an optimal pair if there is no pair with a better form or a better meaning.

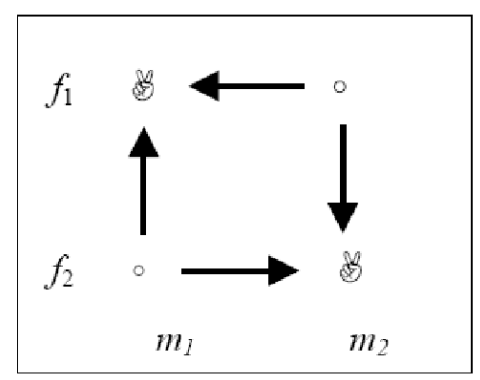

Figure 5. Bidirectional optimisation ${ }^{17}$

Under strong bidirectional optimisation, an optimal pair blocks all other pairs in the same competition. The term "blocking" is used to describe the situation where a possible form or form-meaning pair does not exist because an alternative form or form-meaning pair already does. For example, there are two possible ways to realise the comparative form of good in English - either by means of the regular form gooder or by means of the irregular form better. Because the irregular form better is preferred in English, the regular form gooder is blocked as the comparative form of good. So, in terms of form-meaning pairs, because better (form $f$ ) is preferred to gooder (form $f^{\prime}$ ) for the comparative meaning of good (meaning $m$ ), the form-

\footnotetext{
${ }^{17}$ In bidirectional OT tableaux and figures, optimal pairs are indicated by the victory sign (®).
} 
meaning pair $\langle$ better, comparative meaning of good $\rangle$ is more harmonic than the form-meaning pair $\langle$ gooder, comparative meaning of good $\rangle$, and, as there is no pair more harmonic, the pair $\langle$ better, comparative meaning of good $\rangle$ is then the bidirectionally optimal form-meaning pair. This notion of 'bidirectional optimisation' is illustrated in Figure 5, with the arrows indicating preference relations.

Of course, in language, total blocking of certain form-meaning pairs by optimal pairs does not always occur; rather, we get instances of partial blocking. An example of partial blocking is the relation between kill and cause to die (Blutner 2000). The lexical causative kill is the shorter, less complex form, and is used in the stereotypical causative situation where the action is accomplished in a direct way. However, the longer, more complex form cause to die is not completely blocked by the lexical causative; rather, it is used in more marked situations where the action is accomplished in an indirect way. Take the sentences in (17) for example (Blutner 2000:202). The second sentence, (17b), could be used appropriately when Black Bart caused the sheriff's gun to backfire by stuffing it with cotton, a situation in which the action of killing the sheriff is accomplished in an indirect way.

(a) Black Bart killed the sheriff.

(b) Black Bart caused the sheriff to die.

In order to account for situations where partial blocking occurs, Blutner (2000:203) proposes a recursive variation of bidirectional optimisation, called "weak bidirectional optimisation", or "super-optimality". In weak bidirectional optimisation, a form-meaning pair $\langle f, m\rangle$ is superoptimal if and only if there is no other super-optimal pair $\langle f, m\rangle$ such that $\langle f, m\rangle »\langle f, m\rangle$, and there is no other super-optimal pair $\langle f, m\rangle$ such that $\langle f, m\rangle »\langle f, m\rangle$. The notion of 'super-optimality' can be illustrated by the bidirectional optimisation diagram in Figure 4, in which the arrows point to the preferred pair and the super-optimal pairs are marked with the symbol 8 . If we examine this diagram we see that, under strong bidirectional optimisation, only one pair, $\left\langle f_{1}, m_{1}\right\rangle$ is a bidirectionally optimal pair, as this is the only pair from which no arrows are leaving and towards which two arrows are pointing. However, under weak bidirectional optimisation, the pair $\left\langle f_{2}, m_{2}\right\rangle$ emerges as a super-optimal form-meaning pair as there is no other super-optimal pair that has either a better form for the same meaning or a better meaning for the same form. In Figure 6, the pair $\left\langle f_{2}, m_{2}\right\rangle$ is not in direct competition with the only other super-optimal pair $\left\langle f_{1}, m_{1}\right\rangle$, because they differ in both their form and their meaning component.

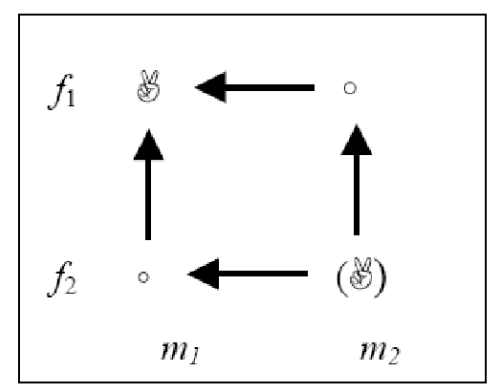

Figure 6. Weak bidirectional optimisation 
This definition of weak bidirectional optimisation allows, in principle, for two types of superoptimal form-meaning pairs: firstly, the strong pair $\left\langle f_{1}, m_{1}\right\rangle$, consisting of an unmarked form and an unmarked meaning, and secondly, the weakly optimal pair $\left\langle f_{2}, m_{2}\right\rangle$, consisting of a marked form and a marked meaning. Both pairs are super-optimal because there are no alternative super-optimal pairs in which either the form is more economical with respect to the same meaning, or the meaning is more adequate with respect to the same form. And so, in language, a suboptimal form $f^{\prime}$ is not blocked entirely, but only as a match to a meaning $m$ which is better paired with an unmarked form $f$ (De Swart 2010:70).

A standard (bidirectional) OT grammar imposes a total ranking order on constraints, meaning that variation and ambiguity are ruled out, as the optimisation of an input generally yields exactly one optimal output. As noted in the previous section, however, both variation and ambiguity are present in the realisation of indefinites in the scope of negation in colloquial Afrikaans. We intend to make use of Bouma's $(2008,2011)$ solution, which adopts Antilla's (1997) conception of stratified, or partial, constraint rankings. A stratified (bidirectional) OT grammar allows for the distribution of the set of universal constraints over different strata, with constraints within strata unranked with respect to one another. When two constraints in one stratum $\{\mathrm{A}, \mathrm{B}\}$ conflict, both the candidate preferred by $\mathrm{A}$ and the candidate preferred by $\mathrm{B}$ will be optimal, allowing for two winning candidates. As Bouma and Hendriks (2011:62) point out, "a stratified ranking $\mathrm{A} »\{\mathrm{~B}, \mathrm{C}\} » \mathrm{D}$ can be seen as denoting a set of compatible, fully specified rankings $\{\mathrm{A} » \mathrm{~B} \gg \mathrm{C} \gg \mathrm{D}, \mathrm{A} \gg \mathrm{C} \gg \mathrm{B} » \mathrm{D}\}$, and a form-meaning pair is optimal when it is optimal under one of the fully specified rankings in this set". This approach therefore predicts both variation in form and ambiguity ${ }^{18}$.

De Swart (2010) provides a detailed discussion of the problems with existing theories of negative indefinites, in view of cross-linguistic variation, pointing out that a (bidirectional) OT analysis allows one to account for both the syntax of negative indefinites and their semantics, and how the form and function of negative indefinites hang together in the syntax-semantics interface. We adopt the same approach in this paper which allows us to distinguish two classes of languages in terms of the OT grammar each language adopts. The essence of the OT analysis is that a language exemplifies negative concord if it has a highly ranked constraint in the syntax that forces the proliferation of special "negative" forms which reflect that the indefinite is in the scope of negation. In order to guarantee that the proliferation of negative indefinites does not lead to multiplication of negation in the semantics, the syntactic constraint favouring the use of negative indefinites must be balanced by a semantic constraint avoiding multiplication of negation in the semantics. If iteration is blocked by such an economy constraint, the resumptive reading will be dominant, leading to the desired single negation reading.

\subsection{Multiple indefinites in the scope of negation in standard Afrikaans}

If we take Afrikaans to consist of two varieties - one variety in which negative spread is possible, and another variety in which negative spread is impossible - then we can characterise the variation in the expression of MNIs in the scope of negation as a result of two different grammars. Such an approach makes use of the OT notion that cross-linguistic differences in the possible realisations of negation in natural language are a result of different grammar-specific

\footnotetext{
${ }^{18} \mathrm{Cf}$. Huddlestone (2010) for an analysis that uses an alternate approach to accounting for variation and ambiguity, namely Stochastic OT (Mattausch 2005, 2007).
} 
rankings of constraints. As such, De Swart's (2010) approach to the analysis of negative indefinites in natural language provides a useful framework.

In Afrikaans, the production of indefinites in the scope of negation is governed by three constraints. Firstly, FNEG, given in (13) above, requires that negation in the input be reflected in the output. This constraint is highly ranked in all varieties of Afrikaans, and is satisfied by a single marker of negation, whether that be a sentence-medial negative marker or a negative indefinite. A second constraint, NegAtTRACT, given in (18), which requires that (clausal) negation be realised on an indefinite in argument or adjunct position, accounts for the strong tendency that languages have "to attract the negative notion to any word that can easily be made negative" (Jespersen 1917:56). This constraint is satisfied when the clausal negation is realised minimally on one indefinite.

\section{NegAtTRACT}

Realise (clausal) negation on an indefinite in argument or adjunct position.

In Afrikaans, NEGATTRACT is ranked high, as the examples in (19) illustrate.

$\begin{array}{llll}\text { (a) Ons het niks } & \text { gekoop } & \text { nie. } \\ \text { we have nothing } & \text { PST-buy } & \text { SN } \\ \text { 'We didn't buy anything.' } & & \end{array}$

\begin{tabular}{|c|c|c|c|c|c|}
\hline $\begin{array}{c}\text { \#Ons } \\
\text { we }\end{array}$ & $\begin{array}{l}\text { het } \\
\text { have }\end{array}$ & $\begin{array}{l}\text { nie } \\
\text { not }\end{array}$ & $\begin{array}{l}(\operatorname{enig}(e)) \text { iets } \\
\text { (any) thing }\end{array}$ & $\begin{array}{l}\text { gekoop } \\
\text { PST-buy }\end{array}$ & $\begin{array}{l}\text { nie. } \quad(* \neg \exists, \vee \exists \neg)^{19} \\
\text { SN }\end{array}$ \\
\hline
\end{tabular}

The picture becomes more complex if there are multiple indefinites in the scope of negation. In order to account for why some languages express negation with MNIs while others do not, a third faithfulness constraint, MAXNEG - given in (20) - requires that all "negative variables", i.e. all indefinites in argument or adjunct position interpreted in the scope of negation, be formally marked with negation.

\section{MAXNeG}

Mark "negative variables" (i.e. mark indefinites in argument or adjunct position that are interpreted in the scope of an anti-additive operator such as negation, as formally negative).

These three faithfulness constraints are in conflict with the markedness constraint *NEG, given in (14), which aims at the reduction of structure in the output by avoiding negation. ${ }^{20}$ In double negation languages, including the prescriptive variety of Afrikaans, ${ }^{*}$ NEG is ranked higher than MAXNEG. This means that when producing multiple indefinites in the scope of negation, a form containing a single negative indefinite together with $\mathrm{n}-1$ indefinites in its scope, is the optimal form for the single negation meaning $\neg \exists \mathrm{x}_{1} \exists \mathrm{x}_{2} \ldots \exists \mathrm{x}_{\mathrm{n}}$. The production of indefinites in the scope of negation is reflected in Tableau 3.

\footnotetext{
19 The hash symbol (\#) indicates that the sentence in (19b), although acceptable for expressing constituent negation - i.e. where there is a specific "something" that we didn't buy - or for expressing a denial of a previous assertion, is not an acceptable way to express the neutral meaning we didn't buy anything, i.e. clausal negation.

${ }^{20}$ As noted in fn. 2, the focus of this paper is on the expression of indefinites under negation, therefore the implications of *NEG on the sentence-final nie in Afrikaans are not addressed in this analysis.
} 
Tableau 3: Production of multiple indefinites in the scope of negation

\begin{tabular}{|l|c|c|c|c|}
\hline$\neg \exists \mathrm{x}_{1} \exists \mathrm{x}_{2}$ & FNEG & NEGATTRACT & $*$ NEG & MAXNEG \\
\hline ooit (enig(e))iets & $* !$ & $* !$ & $*$ & $* *$ \\
nie ooit (enig(e))iets & & & $*$ & $* *$ \\
nooit (enig(e))iets & & & $* * !$ & $*$ \\
nooit niks & & & & \\
\hline
\end{tabular}

When it comes to the interpretation of (multiple) negative indefinites, the situation is far from simple. Whether MNIs are interpreted as negative quantifiers that each contribute their own negation or whether they are interpreted as negative concord items (so-called "n-words") is, according to De Swart and Sag (2002), decided in the grammar and not in the lexicon. De Swart and Sag's central assumption is that negative indefinites (whether negative quantifiers or nwords) are inherently negative and that there are two ways in which a sequence of these elements may be interpreted - either, in negative concord constructions by resumption, or, in double negation constructions, through function application by iteration. What this means is that if a sequence of negative indefinites is interpreted in terms of resumption, through the building of a polyadic quantifier, then a single negation, or negative concord, interpretation results. On the other hand, if a sequence of negative indefinites is interpreted via iteration (function application), this results in a double negation reading. Following Keenan and Westerståhl (1997), De Swart and Sag give the definition of resumptive quantification as in (21), where $\mathrm{E}$ is the universe of discourse, the one-place predicates A1 through Ak represent the restrictors of the quantifiers, and the k-ary predicate $\mathrm{R}$ their scope.

$$
\begin{aligned}
& \text { Resumption of a k-ary quantifier } \\
& \mathrm{Q}^{\prime}{ }_{\mathrm{E}}^{\mathrm{A} 1, \mathrm{~A} 2, \ldots \mathrm{Ak}}(\mathrm{R})=\mathrm{Q}_{\mathrm{Ek}}{ }^{\mathrm{A} 1 \times \mathrm{A} 2 \mathrm{x} \ldots \mathrm{Ak}}(\mathrm{R})
\end{aligned}
$$

(De Swart and Sag 2002:385)

Using French as an example, De Swart (2010:133) illustrates this proposal, showing how in (22) the iteration of two negative quantifiers leads to the generalised quantifier representation in (22b), which has the truth conditions for a double negation interpretation, spelt out in firstorder logic in (22c). In (23), on the other hand, polyadic quantification gives the resumptive quantifier in (23b) - following the definition of "resumption" given in (21) - which has the truth conditions for a negative concord interpretation given in $(23 \mathrm{c})$.

(a)

$$
\begin{array}{lll}
\text { Personne } & \text { n'aime } & \text { personne } \\
\text { nobody } & \text { SN-loves } & \text { nobody }
\end{array}
$$$$
\text { 'Everyone loves someone.' }
$$

(b) NO (HUM, $\{\mathrm{x} \mid \mathrm{NO}(\mathrm{HUM},\{\mathrm{y} \mid \operatorname{LOVE}(\mathrm{x}, \mathrm{y})\})\})$

(c) $\neg \neg \exists \mathrm{x} \neg \exists \mathrm{y} \operatorname{Love}(\mathrm{x}, \mathrm{y})$ (b) $\quad \mathrm{NO}_{\mathrm{E} 2}$ hum $\times$ hum $(\mathrm{LOVE})$
(French)

(double negation)
$\begin{array}{ll}\text { Personne } & n \text { 'aime } \\ \text { nobody } & \text { SN-loves } \\ \text { 'No one loves anyone.' }\end{array}$
(a)
(French) nobody
(negative concord) 
(c)

$$
\neg \exists \mathrm{x} \exists \mathrm{y} \operatorname{Love}(\mathrm{x}, \mathrm{y})
$$

The formal semantic analysis developed in De Swart and Sag (2002) accounts for how languages may allow both double negation and negative concord, and explains - if a language has a preference for either double negation or negative concord - how the interpretation of negative indefinites takes place. However, it is not able to predict whether a language will have a preference for one interpretation over another. This is where bidirectional OT comes in as a way to account for the cross-linguistic variation on the basis of the interaction between violable constraints. De Swart (2010) points out that iteration is the preferred method of interpretation of MNIs as it can be defined in terms of first-order logic. She therefore proposes the constraint INTNEG, a faithfulness constraint that mandates the interpretation of every negative indefinite in an input form as contributing a semantic negation at the first-order level in the output.

\section{INTNEG}

Force iteration (i.e. interpret every negative indefinite in the input form as contributing a semantic negation at the first-order level in the output).

As a faithfulness constraint, INTNEG is in conflict with the markedness constraint *NEG because, while it is generally preferable for interpretation of MNIs to take place via iteration as it is first-order definable, this involves multiplying the negation in the output. *NEG, on the other hand, mitigates against (multiple) negation in the output. For this reason, if *NEG is ranked higher than INTNEG, iteration of negative indefinites will not be the preferred method of interpretation. In such a case, the interpretation of MNIs will take place via resumption of a polyadic quantifier, which will result in a single negation interpretation. Cross-linguistic variation is then seen to be the result of language-specific orderings of the same set of constraints. Therefore, the relative ordering of INTNEG and *NEG results in either languages with negative concord interpretations of expressions containing MNIs (negative concord languages) or languages with double negation interpretations of expressions containing MNIs (double negation languages).

In prescriptive, standard Afrikaans, INTNEG is ranked higher than *NEG. This means that the interpretation of MNIs takes place via iteration, and every negative indefinite is interpreted as contributing its own semantic negation. This entails that when a construction containing MNIs is produced, all the negative indefinites contribute a negation to the interpretation. The interpretation of MNIs in standard Afrikaans is reflected in Tableau 4.

Tableau 4: Interpretation of MNIs in standard Afrikaans

\begin{tabular}{|c|c|c|c|c|}
\hline nooit niks & FNEG & NEGATTRACT & INTNEG & *NEG \\
\hline$\neg \exists \mathrm{x}_{1} \exists \mathrm{x}_{2}$ & & & $* !$ & $*$ \\
$\neg \exists \mathrm{x}_{1} \neg \exists \mathrm{x}_{2}$ & & & & $* *$ \\
\hline
\end{tabular}

The generation and interpretation of multiple indefinites under negation in standard Afrikaans can be further represented in bidirectional OT, as illustrated in Tableau 5, allowing us to account for the (highly marked) occurrence of MNI combinations with a double negation interpretation. The competition represented by this tableau is one between paired forms and meanings $(\langle f, m>)$, and bidirectional optimisation over these form-meaning pairs results in the selection of one or more super-optimal pairs. Pairs that are suboptimal in one or other direction of optimisation are 
blocked. So, even though a meaning might be optimal, if its paired form is suboptimal (in relation to another form), the pair is blocked; likewise if a form is optimal but its paired meaning is suboptimal (in relation to another meaning), then that pair is also blocked.

Tableau 5: MNIs in standard Afrikaans (production and interpretation)

\begin{tabular}{|l|l|c|c|c|c|}
\hline form-meaning pairs & FNEG & NEGATTRACT & INTNEG & *NEG & MAXNEG \\
\hline$<$ nooit iets, $\neg \exists \mathrm{x}_{1} \exists \mathrm{x}_{2}>$ & & & & $* *$ & $*$ \\
$<$ nooit iets, $\neg \exists \mathrm{x}_{1} \neg \exists \mathrm{x}_{2}>$ & & & & $* * *$ & $*$ \\
$<$ nooit niks, $\neg \exists \mathrm{x}_{1} \exists \mathrm{x}_{2}>$ & & & $*$ & $* * *$ & \\
$<$ nooit niks, $\neg \exists \mathrm{x}_{1} \neg \exists \mathrm{x}_{2}>$ & & & & $* * * *$ & \\
\hline
\end{tabular}

In Tableau 5, the form nooit iets is the optimal form for expressing the meaning $\neg \exists \mathrm{x}_{1} \exists \mathrm{x}_{2}$. This is a result of the fact that the only other form competing to express this meaning, nooit niks, loses out as it incurs an extra violation of *NEG. The meaning $\neg \exists \mathrm{x}_{1} \exists \mathrm{x}_{2}$, in turn, is suboptimal as an interpretation of the form nooit niks as it violates INTNEG. We are then left with two possible forms for expressing the meaning $\neg \exists \mathrm{x}_{1} \neg \exists \mathrm{x}_{2}$ : nooit iets and nooit niks. However, in standard generalised quantifier theory, the interpretation of sequences of quantifiers is derived by function application, which means that in order to derive a meaning consisting of two negations, there would have to be two negative quantifiers in the form. The restrictions that generalised quantifier theory place on the function that specifies the set of possible candidate meanings for a particular structure therefore exclude the form nooit iets as a possible form for expressing the meaning $\neg \exists \mathrm{x}_{1} \neg \exists \mathrm{x}_{2}$ (hence the grey row in the tableau). ${ }^{21} \mathrm{We}$ are therefore left with the form nooit niks as the optimal form for expressing the meaning $\neg \exists \mathrm{x}_{1} \neg \exists \mathrm{x}_{2}$, and vice versa.

This analysis is able to account for the observation that in prescriptive, standard Afrikaans (the conservative variety of the language), the way of realising indefinites in the scope of negation is with NI-NNI combinations, while MNI combinations always yield a double negation reading, although the account presented here does not accommodate the observation that a particular double negation prosodic contour is necessary for the latter. However, because of the strict ranking of constraints in ordinal OT, this analysis is unable to account for the variation, with regard to the production of multiple indefinites in the scope of negation, present in colloquial Afrikaans (as discussed in section 2.1). In order to account for this variation, we have to make use of an approach that predicts variation, namely Bouma's $(2008,2011)$ stratified bidirectional OT, as discussed briefly in section 3.1.

\subsection{Multiple negative indefinites in colloquial Afrikaans}

In the previous section, three constraints were discussed which govern the expression and interpretation of indefinites in the scope of negation in standard Afrikaans, namely *NEG, MaxNeg and IntNeg. According to De Swart (2010), the ranking of *Neg and MaxNeg accounts for the cross-linguistic variation in the expression of indefinites in the scope of negation in negative concord vs. double negation languages, while the ranking of $*$ NEG and

\footnotetext{
${ }^{21}$ Following De Swart (2010:61), we consider candidates generated by the function INT, which specifies the set of candidate meanings for a particular expression, to be constrained by a correspondence function between forms and interpretations. Candidates generated by INT are taken to be constrained by standard semantic theories such as type theory, the lambda calculus, and generalised quantifier theory.
} 
INTNEG accounts for cross-linguistic variation in the interpretation of MNIs. These constraints should therefore be sufficient to account for the variation in colloquial Afrikaans.

De Swart (2010:142) argues that only rankings where MAXNEG and INTNEG are distributed on either side of *NEG reflect viable options for a linguistic system that balances generation and interpretation of negative utterances. The argument is that if INTNEG and MAXNEG are ranked lower than $* \mathrm{NEG}$, then an MNI form will not be motivated by the low ranking of MAXNEG, even if the ranking leads to a negative concord interpretation of such constructions. However, if we make use of Bouma's $(2008,2011)$ conception of stratified OT $^{22}$, we can take *NEG and MAXNEG as occurring in the same stratum (and are therefore unranked with regard to each other), the variation in the expression of multiple indefinites in the scope of negation arises, and the unbalanced nature of the constraint ranking is overcome. The two possible rankings of these constraints are shown in (25):

*NEG » MAXNEG » INTNEG

(b) MAXNEG »*NEG »INTNEG

When the input meaning is a negative concord meaning, the production optimisation proceeds under the two possible constraint rankings given in (25). In effect, both outputs incur the same number of violations and, as pointed out in section 3.1, are both winning candidates. The conflict between the two constraints within a single stratum therefore results in variation: one input is mapped to two outputs. Furthermore, the interpretation optimisation also proceeds under the two constraint rankings given in (25), depending on the output of the production optimisation. However, as MAXNEG and INTNEG do not interact directly, the outcome is a negative concord interpretation in both cases. The assumption here is that the input form is an MNI combination produced with a neutral prosodic contour. If a double negation prosodic contour were present, then we would be analysing a different form-meaning pair, one that would be subject to further faithfulness constraints requiring the marking of prosodic prominence and the interpretation of such prosodic information, something related to Biberauer and Zeijlstra's (2012) Negative Verum Focus. The result of the bidirectional optimisation over form-meaning pairs without double negation prosody is given in Tableau 6 , where the vertical dotted line indicates the unranked constraints, i.e. constraints within the same stratum.

\footnotetext{
${ }^{22}$ See also Klimak-Jankowska (2012) for the use of stratified bidirectional OT to model variation and ambiguity in the expression and interpretation of Polish bare habituals.
} 
Tableau 6: Production and interpretation of MNIs in colloquial Afrikaans

\begin{tabular}{|c|c|c|c:c|c|}
\hline $\begin{array}{c}\text { Meaning } \\
\neg \exists \mathrm{x}_{1} \exists \mathrm{x}_{2}\end{array}$ & FNEG & NEGATTRACT & $*$ NEG & MAXNEG & INTNEG \\
\hline $\begin{array}{l}\text { nooit iets } \\
\text { nooit niks }\end{array}$ & & & $*$ & $*$ & \\
\hline $\begin{array}{c}\text { Form } \\
\text { nooit niks }\end{array}$ & FNEG & NEGATTRACT & $*$ NEG & MAXNEG & INTNEG \\
\hdashline$\exists \mathrm{x}_{1} \exists \mathrm{x}_{2}$ & & & $* !$ & & $*$ \\
\hline $\begin{array}{c}\neg \text { nooit } \text { iets } \\
\neg \mathrm{x}_{2}\end{array}$ & & & & & \\
\hline$\neg \mathrm{x}_{1} \exists \mathrm{x}_{2}$ & & & $* *$ & & $*$ \\
$\neg \exists \mathrm{x}_{1} \neg \exists \mathrm{x}_{2}$ & & & & & \\
\hline
\end{tabular}

What appears to be crucial here is that the hearer must take a speaker's perspective into account in order to correctly interpret an utterance, as assigning a meaning to an utterance is not an arbitrary exercise. Bidirectional optimisation, the combination of production (the speaker's perspective) and comprehension (the hearer's perspective) allows one to account for the interpretation of MNIs in colloquial Afrikaans. Under this approach, the hearer must reconstruct the speaker's intention in order to interpret the utterance. If we therefore consider the grammar proposed here to be bidirectional, we end up with a grammar in which the hearer's optimisation involves both the syntactic and semantic constraints governing the expression and interpretation of multiple indefinites in the scope of negation.

\section{Conclusion}

The aim of this paper was to provide a bidirectional OT analysis of multiple indefinites in the scope of negation in Afrikaans. In order to achieve this aim, a description of the occurrence of these (negative) indefinites in Afrikaans was presented, with particular focus on the gradience of acceptability of MNI combinations, as determined by perception experiments, and the frequency of such constructions in a written corpus of Afrikaans. We have shown that although multiple indefinites in the scope of negation are generally realised by one negative indefinite together with any number of non-negative indefinites, it is possible for MNI constructions to occur in Afrikaans. Further, we pointed out that although infrequent, these MNI combinations are prescriptively assigned a double negation interpretation in standard Afrikaans. However, both the corpus data and the experimental data show that MNI combinations, contrary to expectations, are in fact generally assigned a negative concord interpretation. The analysis presented in this paper suggests that when MNI combinations are produced with a specific contradictory prosodic contour, associated with double negation constructions, they are typically associated with the prescriptive, standard variety of the language and assigned a double negation interpretation. However, when MNIs are produced with a neutral prosodic contour, they are assigned a negative concord interpretation. The variation in form and interpretation of multiple (negative) indefinites in the scope of negation in Afrikaans is accounted for by three constraints, namely *NEG, MAXNEG and INTNEG. We argue that in a partially ranked, stratified OT grammar, *NEG and MAXNEG are in the same stratum and as such give rise to two possible constraint rankings and consequently two winning candidates for the generation of utterances containing indefinites in the scope of negation in colloquial Afrikaans. In line with other cross-linguistic observations on the production of 
negative concord and double negation MNI constructions, this paper shows that the different rankings of universal constraints governing the production and interpretation of negative indefinites can account for variation in the expression, and the apparent ambiguity in the interpretation, of indefinites in the scope of negation in standard and colloquial Afrikaans in a bidirectional OT model in which the hearer must take the speaker's perspective into account.

\section{Acknowledgements}

This material is based on work financially supported by the National Research Foundation (NRF). Any opinion, findings, conclusions or recommendations expressed in this material are those of the authors and therefore the NRF does not accept any liability in regard thereto.

\section{References}

Anttila, A. 1997. Deriving variation from grammar. In F.L. Hinskens, R. van Hout and W.L. Wetzels (eds.) Variation, change, and phonological theory. Amsterdam: John Benjamins. pp. $35-68$.

Anttila, A. and V. Fong. 2004. Variation, ambiguity, and noun classes in English. Lingua 114: 1253-1290.

Beckman, M.E. and G.A. Elam. 1997. Guidelines for ToBI labelling. Version 3. Columbus: Ohio State University, Department of Linguistics.

Bell, A. 2004. How N-words move: Bipartite negation and 'Split-NegP'. In A. Breitbarth and H. van Riemsdijk (eds.) Triggers. Amsterdam: Mouton de Gruyter. pp. 77-114.

Bernini, G. and P. Ramat. 1996. Negative sentences in the languages of Europe: A typological approach. Berlin and New York: Mouton de Gruyter.

Biberauer, T. 2008. Doubling and omission: Insights from Afrikaans negation. In S. Barbiers, M. van der Ham, O. Koeneman and M. Lekakou (eds.) Microvariations in syntactic doubling. Bingley: Emerald. pp. 103-140.

Biberauer, T. 2009. Jespersen off course? The case of contemporary Afrikaans negation. In E. van Gelderen (ed.) Cyclical change. Amsterdam: John Benjamins. pp. 91-130.

Biberauer, T. and H. Zeijlstra. 2012. Negative concord in Afrikaans: Filling a typological gap. Journal of Semantics 29(3): 345-371.

Blutner, R. 2000. Some aspects of optimality in natural language interpretation. Journal of Semantics 17(3): 189-216.

Blutner, R., H. de Hoop and P. Hendriks. 2006. Optimal communication. Stanford, CA: CSLI Publications. 
Bouma, G. 2008. Starting a Sentence in Dutch: A Corpus Study of Subject- and ObjectFronting. Doctoral dissertation, University of Groningen.

Bouma, G. 2011. Production and comprehension in context: The case of word order freezing. In A. Benz and J. Mattausch (eds.) Bidirectional Optimality Theory. John Benjamins. pp. 169-190.

Bouma, G. and P. Hendriks. 2011. Partial word order freezing in Dutch. Journal of Logic, Language and Information 21(1): 53-73.

De Swart, H. 2010. Expression and interpretation of negation. Berlin: Springer.

De Swart, H. and I.A. Sag. 2002. Negation and negative concord in romance. Linguistics and Philosophy 254: 373-417.

Den Besten, J. 1986. Double negation and the genesis of Afrikaans. In P. Muysken and N. Smith (eds.) Substrata versus universals in Creole languages. Amsterdam: John Benjamins. pp. 185-230.

Donaldson, B.C. 1993. A grammar of Afrikaans. Berlin: Mouton de Gruyter.

Espinal, M.T. and P. Prieto. 2011. Intonational encoding of double negation in Catalan. Journal of Pragmatics 43: 2392-2410.

Hendriks, P., H. de Hoop, I. Krämer, H. de Swart and J. Zwarts. 2010. Conflicts in Interpretation. Sheffield: Equinox Publishing.

Huddlestone, K.M. 2010. Negative Indefinites in Afrikaans. Doctoral dissertation, Utrecht University.

Jespersen, O. 1917. Negation in English and other languages. Copenhagen: Host.

Keenan, E. and D. Westerståhl. 1997. Generalized quantifiers in linguistics and logic. In J. van Benthem and A. ter Meulen (eds.) Handbook of logic and language. Amsterdam: Elsevier. pp. 837-893.

Klimek-Jankowska, D. 2012. Imperfective and perfective habituals in Polish: A bi-directional OT account of variation and ambiguity. Journal of Logic, Language and Information 21(1): 31 52.

Laka, I. 1990. Negation in Syntax. Doctoral dissertation, MIT.

Liberman, M. and I.A. Sag. 1974. Prosodic form and discourse function. In M. La Galy et al. (eds.) Papers from the tenth regional meeting of the Chicago Linguistics Society. Chicago: Chicago Linguistics Society. pp. 416-427.

Mattausch, J. 2005. On the optimization and grammaticalization of anaphora. ZAS Papers in Linguistics 38. 
Mattausch, J. 2007. Optimality, bidirectionality and the evolution of binding phenomena. Research on Language and Computation 5: 103-131.

May, R. 1989. Interpreting logical form. Linguistics and Philosophy 12(4): 387-435.

Molnárfi, L. 2004. On the interpretation of multiple negation in spoken and written Afrikaans. In A. ter Meulen and W. Abraham (eds.) The composition of meaning: From lexeme to discourse. Amsterdam: John Benjamins. pp. 195-225.

Oosthuizen, J. 1998. The final 'nie' in Afrikaans negative sentences. Stellenbosch Papers in Linguistics 31: 61-93.

Penka, D. 2007. Negative Indefinites. Doctoral dissertation, University of Tübingen.

Ponelis, F.A. 1993. The development of Afrikaans. Frankfurt am Main: Lang.

Prieto, P., J. Borràs-Comes, S. Tubau and M.T. Espinal. 2013. Prosody and gesture constrain the interpretation of double negation. Lingua 131: 136-150.

Prince, A. and P. Smolensky. 1997. Optimality: From neural networks to Universal Grammar. Science 275: 1604-1610.

Puskás, G. 2006. Double negation and information structure: Somewhere between topic and focus. In V. Molnár and S. Winkler (eds.) The architecture of focus. Studies in Generative Grammar 82. Berlin, New York: Mouton de Gruyter. pp. 291-317.

Puskás, G. 2012. Licensing double negation in negative concord and non-negative concord languages. Natural Language and Linguistic Theory 30(2): 611-649.

Robbers, K. 1992. Properties of negation in Afrikaans and Italian. In R. Bok-Bennema and R.V. van Hout (eds.) Linguistics in the Netherlands 1992. Amsterdam: John Benjamins. pp. 223234.

Schafer, A.J., S.R. Speer, P. Warren and S.D. White. 2000. Intonational disambiguation in sentence production and comprehension. Journal of Psycholinguistic Research 29(2): 169-182.

Van Benthem, J. 1989. Polyadic quantifiers. Linguistics and Philosophy 12: 437-464.

Van der Wouden, T. 1994. Negative Contexts. Doctoral dissertation, University of Groningen.

Wilson, C. 2001. Bidirectional optimization and the theory of anaphora. In G. Legendre, J. Grimshaw and S. Vikner (eds.) Optimality-theoretic syntax. Cambridge, MA: MIT Press. pp. 465-507.

Zeevat, H. 2000. The asymmetry of optimality theoretic syntax and semantics. Journal of Semantics 17(3): 243-262.

Zeevat, H. 2006. Freezing and marking. Linguistics 44(5): 1095-1112. 
Zeijlstra, H. 2004. Sentential Negation and Negative Concord. Doctoral dissertation, University of Amsterdam.

Zeijlstra, H. 2007. Emphatic multiple negative expressions in Dutch: A by-product of the loss of negative concord. ACLC Working Papers 2(1): 77-103. 